\title{
Investigation on the Level of Evidence in Researches Done by Orthopedic Residents of the Department of Orthopedics, Philippine General Hospital over the Past Twenty-seven Years
}

\author{
Emmanuel P. Estrella, ${ }^{1,2}$ Nathaniel S. Orillaza, Jr. ${ }^{1,2}$ and Ana Cristina D. Decenteceo ${ }^{1}$
}

${ }^{1}$ Microsurgery Unit, Department of Orthopedics, College of Medicine and Philippine General Hospital, University of the Philippines Manila ${ }^{2}$ ASTRO (Advanced STudy and Research in Orthopedics) Study Group, National Institutes of Health, University of the Philippines Manila

\begin{abstract}
Background. Clinical research has been part of the orthopedic residents' training program over the past 27 years of the Department of Orthopedics, Philippine General Hospital. The purpose of the present study was to determine the levels of evidence in the researches done by orthopedic residents in training from January 1983 to December 2010.

Methods. The authors reviewed all completed research performed by the department's orthopedic residents in training from January 1983 to December 31, 2010. The exclusion criteria for the study were as follows: review articles, research articles whose full texts were not available and those research articles in which consultants were primary authors. The research articles were scored according to the level of evidence proposed by the Journal of Bone and Joint Surgery (American Volume), and were categorized according to decade: 1980 s, 1990s, and 2000 s.
\end{abstract}

Results. A total of 224 research articles were retrieved and reviewed. There were no Level I studies performed in the department by the residents since 1983 . There was a significant increase in the number of Level II and Level III studies from the 1980 s to the 2000s $(p=0.0001)$. The Hand Section had the highest number of Level II studies $8.6 \%$ (3 out of 35 ) while the Adult Section had the highest number of Level III studies at $21 \%$ (11 out of 53). The Pediatric Section had the highest number of Level IV studies at $91 \%$ (30 out of 33).

Conclusion. The level of evidence in research conducted by the orthopedic residents in training of the Department of Orthopedics, Philippine General Hospital has improved significantly in the past 27 years.

Key Words: level of evidence, orthopedic residents, residents' research, research in orthopedic training

Corresponding author: Emmanuel P. Estrella, MD

Microsurgery Unit, Department of Orthopedics

Philippine General Hospital

University of the Philippines Manila

Taft Avenue, Ermita, Manila 1000 Philippines

Telephone: +6325548466

Email: estee96@yahoo.com
Introduction

The level of evidence in clinical research was proposed by Sackett ${ }^{1}$ in 1986. The Journal of Bone and Joint Surgery American has adopted the levels of evidence for considering research for publication ${ }^{2}$ (Table 1). The popularity of evidence-based medicine in recent years has made clinicians base their clinical practice to Level I studies or randomized controlled trials. However, in a surgical field such as orthopedics, such studies are not common. A study on the levels of evidence in orthopedic journals showed that only $32 \%$ were Level I and Level II studies compared with $68 \%$ that were Level III and Level IV studies ${ }^{3}$ and that higher levels of evidence in major orthopedic journals are lacking. ${ }^{4}$ The current study also showed that higher impact journals will tend to accept more Level I and Level II studies.

Few studies have reported levels of evidence in research conducted by orthopedic residents in training. However, one study showed that the knowledge of orthopedic residents regarding the classification of studies according to levels of evidence was lacking and that residents need to be better educated on this aspect during residency. ${ }^{5}$ The hierarchy of the level of evidence in orthopedic research will enable residents-in-training to be guided on the best available evidence in orthopedic care. This will in turn guide them as orthopedists in managing their patients.

The Department of Orthopedics of the Philippine General Hospital started its residency program in 1971, and started to require residents in training to produce clinical or basic science researches as part of its training program in 1983. The department was divided into five sections: Adult, Hand and Microsurgery, Pediatric Orthopedics, Spine, and Trauma. The division was intended to strengthen the subspecialties by assigning consultants to manage their areas of expertise. This was also done in such a way to easily compile cohorts within a small group of consultants for research purposes. Residents with interest in certain conditions were under the guidance of consultants to work on topics under that section.

Since research production was one of the requirements for graduation in the orthopedic residency program, orthopedic residents have produced a number of research articles under the tutelage of consultant orthopedic surgeons 
who serve as secondary authors. As a training institution, there is a need to evaluate the level of clinical research produced through the years. The purpose of this study was to determine the levels of evidence in the research conducted by orthopedic residents in training from its inception in January 1983 to December 2010.

\section{Methods}

All completed research conducted by orthopedic residents in training from January 1983 to December 2010 were retrieved from the department archives and reviewed. The following were excluded from analysis: review articles, incomplete research, research articles whose full texts were not available and those research articles in which consultants were primary authors. All research articles were identified through annual department reports and a compilation of research through the years made by the department and by the hospital. The search was limited to available articles compiled in the research archives. After reviewing the original full text articles, a data extraction sheet was made specifically for this study. The research articles were then categorized into levels of evidence, ${ }^{2}$ to the decade when it was completed (1980s (1983-1989), 1990s (1990-1999) and 2000s (2000-2010)), and to the section in which the research was conducted. The original full text articles were independently reviewed by the three authors.
The following data was extracted: Authors, year of production, section where the research was conducted, study type/design, and the level of evidence of the research article. ${ }^{3}$ Once completed, any disagreements in the data gathered by the review authors were resolved by consensus. The final level of evidence for a particular paper was decided upon by the most senior author.

\section{Statistical and Data Analysis}

All data were encoded in Microsoft Excel XP 2003 and analyzed with STATA v10 (Houston, TX) statistical software. Results were expressed as percentages and a chi-square test was used to determine significant differences between two groups. In cases where more than two groups were compared, Kruskall-wallis test was used. A p-value of $\leq 0.05$ was considered significant for all statistical tests.

\section{Results}

From 1983 to 2010, there were a total of 446 papers reported finished by the residents. A total of 224 full text research articles were able to fulfill the inclusion criteria and were available for review. There were a total of 111 articles in the 80s, 50 articles in the 90s and 63 articles for the 2000s (Table 2). The total number of articles that were included in this study was expressed as a percentage of the total number of articles included in that decade (Table 2). There were no

Table 1. Levels of evidence in clinical research

\begin{tabular}{|c|c|c|c|c|}
\hline & Therapeutic Studies & Prognostic Studies & Diagnostic Studies & $\begin{array}{c}\text { Economic and Decision } \\
\text { Analysis }\end{array}$ \\
\hline Level I & $\begin{array}{l}\text {-High Quality RCT11 } \\
\text {-SR }{ }^{2} \text { of Level I studies }\end{array}$ & $\begin{array}{l}\text {-High quality prospective study( } \geq \\
80 \% \text { follow-up) } \\
\text {-SR of Level I studies }\end{array}$ & $\begin{array}{l}\text {-Testing of previously developed } \\
\text { diagnostic criteria in series of } \\
\text { consecutive patients (with } \\
\text { universally applied reference } \\
\text { "gold" standard) } \\
\text {-SR of Level I studies }\end{array}$ & $\begin{array}{l}\text {-Sensible costs and } \\
\text { alternative; multi-way } \\
\text { sensitivity analysis. } \\
\text {-SR of level I studies }\end{array}$ \\
\hline Level II & $\begin{array}{l}\text {-Lesser Quality RCT (eg. < } 80 \% \\
\text { follow-up no blinding, or improper } \\
\text { randomization) } \\
\text {-SR of Level II studies or Level I } \\
\text { studies with Inconsistent results } \\
\text {-Prospective comparative Study }\end{array}$ & $\begin{array}{l}\text {-Retrospective Study } \\
\text {-Lesser quality prospective study } \\
\text { (eg. }<80 \% \text { follow-up enrolled at } \\
\text { different time points) } \\
\text {-untreated controls from an RCT } \\
\text {-SR of level II studies }\end{array}$ & $\begin{array}{l}\text {-Development of a diagnostic } \\
\text { criteria (with a universally } \\
\text { applied reference "gold } \\
\text { standard") } \\
\text {-SR of level II studies }\end{array}$ & $\begin{array}{l}\text {-Sensible costs and } \\
\text { alternatives (limited studies); } \\
\text { multiway sensitivity analyses } \\
\text {-SR of level II studies }\end{array}$ \\
\hline Level III & $\begin{array}{l}\text {-Case-Control Study } \\
\text {-Retrospective comparative study } \\
\text {-SR of level III studies }\end{array}$ & -Case-control Study & $\begin{array}{l}\text {-Study of non-consecutive } \\
\text { patients (without consistently } \\
\text { reference) } \\
\text {-SR of level III studies }\end{array}$ & $\begin{array}{l}\text {-Analyses based on limited } \\
\text { alternatives and costs; poor } \\
\text { estimates } \\
\text {-SR of level III studies }\end{array}$ \\
\hline Level IV & Case Series & Case Series & $\begin{array}{l}\text { Case-Control Study } \\
\text { Poor reference standard }\end{array}$ & No sensitivity analysis \\
\hline Level V & Expert Opinion & Expert Opinion & Expert Opinion & Expert Opinion \\
\hline
\end{tabular}

Table 2. Level of evidence of researches conducted by orthopedic residents, by Decade

\begin{tabular}{llll}
\hline Level of Evidence & \multicolumn{1}{c}{ 1980s } & 1990s & 2000s \\
\hline Level I & $0 / 111(0 \%)$ & $0 / 50(0 \%)$ & $0 / 63(0 \%)$ \\
Level II & $1 / 111(0.9 \%)$ & $1 / 50(2 \%)$ & $4 / 63(6.3 \%)$ \\
Level III & $11 / 111(9.9 \%)$ & $3 / 50(6 \%)$ & $17 / 63(27 \%)$ \\
Level IV & $95 / 111(85.6 \%)$ & $32 / 50(64 \%)$ & $30 / 63(48 \%)$ \\
Level V & $0 / 111(0 \%)$ & $0 / 50$ & $0 / 63$ \\
Basic Science & $4 / 111(3.6 \%)$ & $14 / 50(28 \%)$ & $124 / 224(14 \%)$ \\
\end{tabular}


Table 3. Level of evidence of research conducted, by Section

\begin{tabular}{llllllll}
\hline & Hand & Trauma & Pedia & Adult & Spine & MultiSection & TOTAL \\
\hline Level I & 0 & 0 & 0 & 0 & 0 & 0 & 0 \\
Level II & $3(8.6 \%)$ & $2(4.3 \%)$ & $1(3 \%)$ & $0(0 \%)$ & $0(0 \%)$ & $0(0 \%)$ & 6 \\
Level III & $4(11.4 \%)$ & $5(10.9 \%)$ & $1(3 \%)$ & $11(21 \%)$ & $4(17 \%)$ & $6(18 \%)$ & 31 \\
Level IV & $23(65.7 \%)$ & $36(78.3 \%)$ & $30(91 \%)$ & $37(70 \%)$ & $17(71 \%)$ & $14(42 \%)$ & 157 \\
Level V & $0(0 \%)$ & $0(0 \%)$ & $0(0 \%)$ & $0(0 \%)$ & $0(0 \%)$ & $0(0 \%)$ & 0 \\
Basic Science & $5(14.3 \%)$ & $3(6.5 \%)$ & $1(3 \%)$ & $5(9 \%)$ & $3(12 \%)$ & $13(40 \%)$ & 30 \\
TOTAL & 35 & 46 & 33 & 53 & 24 & 33 & 224 \\
\hline
\end{tabular}

Level I studies performed in the department by the residents since 1983. There was a significant increase in the number of Level II studies from $0.9 \%$ (1 out of 111 ) in the 80 s to $6.3 \%$ (4 out of 63 ) in the 2000s. There was also an increase in Level III studies from $9.9 \%$ (11 out of 111 ) in the 80 s to $27 \%$ (17 out of 63 ) in the 2000s. This was significant ( $p=0.0001)$. There was also a significant decrease in the number of Level IV studies from $85.6 \%$ (95 out of 111 ) in the 80 s to $48 \%$ (30 out of 63 ) in the 2000s. The average level of evidence slightly improved from 3.9 in the 80 s to 3.5 in the 2000s. Basic science research increased from $3.6 \%$ (4 out of 111) in the 80 s to $19 \%$ (12 out of 63) in the 2000s.

The Hand Section had the highest number of Level II studies at $8.6 \%$ (3 out of 35 ) followed by the Trauma $(4.3 \%$ ) and Pediatric Orthopedics Sections (3\%). The Adult Section had the highest number of Level III studies at $21 \%$ (11 out of 53) followed by the Spine Section. The Pediatric section had the highest number of Level IV studies at 91\% (30 out of 33) (Table 3).

We also analyzed research production by section through the decades. The Hand section was the only section that increased its research production from the 1980s to 2000s, based on the articles retrieved (Table 4).

Table 4. Researches by Section by Decade done by residents in training

\begin{tabular}{lccc}
\hline \multicolumn{1}{c}{ Section } & 1980s & 1990s & 2000s \\
\hline Hand & 9 & 7 & 19 \\
Trauma & 29 & 7 & 10 \\
Pediatrics & 20 & 8 & 5 \\
Adult & 32 & 4 & 17 \\
Spine & 15 & 3 & 6 \\
MultiSection $^{1}$ & 6 & 21 & 6 \\
\hline
\end{tabular}

${ }^{1}$ MultiSection: More than two sections were involved in the research

\section{Discussion}

The present study showed an increase in the level of evidence in research conducted by orthopedic residents in training for the Department of Orthopedics. At present, we are not aware of any other study investigating the level of evidence in research conducted by orthopedic residents in training through the years. This step will enable the department to examine its role in increasing the level of evidence and quality of research conducted by their residents. Although the quality of research is influenced by several factors, the significant percentage increase in Level II and Level III papers represents improvement in how research is conducted. Level II papers surged in the last decade, influenced by an understanding of ways to design randomized trials without affecting the integrity and ethics of patient management. Another potential factor was the restructuring of the residency research process in 2004 where residents were given two years instead of one year to finish their research. We also note that around 2002-2004, formal research workshops and didactics on clinical research were instituted by the research committee to enable residents to understand the process of research production from protocol formation to research implementation and writing. Although it decreased the number of finished papers per year, it gave more time for quality research papers to be produced. Better collection of cases has also shifted papers from case reports which were quite common in the 1980s to at least case series, which made case reports almost nonexistent in the 2000s. However, case reports will remain an integral part of research, were never discouraged and were continually conducted outside the requirements of residency training.

The lack of Level I papers produced in the department reflects the general trend in the surgical community. ${ }^{6}$ Aside from the difficulty in designing and producing good quality randomized trials in the surgical field, ${ }^{6}$ it takes a long time to finish recruitment, and data collection usually needs to continue beyond the tenure of an orthopedic resident. A large concentration of research was still in general orthopedics, specifically on adult and trauma orthopedics. This reflects the common conditions encountered in the department and the bulk of cases being seen by the residents. However, by the 2000s, we saw an increase in the number of research produced by the Hand Section, such that it was the only section which increased its research production since the 1980s. However, this was limited to the number of articles retrieved by the authors.

Research can be improved by establishing a welldesigned and user-friendly database of common conditions seen in the department. This will allow comprehensive and accurate collection of data for future use. With regard to time, the best set-up is still a consultant-initiated and managed research, which is not bound by the years of residency. Level I studies were not conducted in the past 30 
years by residents-in-training. Among the obstacles that were cited in literature was the inclusion of sham procedures in surgery. ${ }^{7}$ However, some clinicians believe that with proper design, a randomized trial with sham control is possible. $^{8}$

Most, if not all orthopedic residents when they start their residency program will have at least some exposure to research. Publication prior to entry to the residency program by an incoming resident in the department is almost nonexistent. This is in contrast to a study conducted by the American Association of Medical Colleges in 2006, wherein most of the applicants accepted in orthopedic residency programs had at least one publication. ${ }^{9}$

The papers included in the study were limited to the available printed copies in the department archive. The 50\% accrual rate was very low and was a major limitation of this study. Although we had 224 articles for review, the addition of the other $50 \%$ could have given us a better picture of the current level of evidence of research conducted by residentsin-training. Another limitation of the study was the assessment of the authors on the level of evidence for each research paper reviewed. Although consensus was required to decide on the appropriate level, two studies have shown that the experience of the reviewer did not change the scoring of an article regarding its level of evidence if the level of evidence table ${ }^{2}$ was available at the time of review, which the present authors followed at the time of the review. ${ }^{3,10}$

Research forms the bedrock on which knowledge in clinical training and treatment lies. It will continue to evolve and provide orthopedists the best possible evidence to treat their patients. This is after all the ultimate goal of any clinician. The present study showed a significant shift towards level III and IV evidence in residents' research over the past three decades and there is a need to improve this. Most of the researches produced by residents provided Level IV evidence. The level of evidence in such studies may be improved by including a control group, thus increasing the level of evidence to Level III. ${ }^{6}$

In summary, there is a need to improve the level of evidence in research being conducted by orthopedic residents in training. A structured program in research where residents in training will be provided with the added knowledge on the anatomy and physiology of research will certainly help. We envision a future in which orthopedic residents in training will conduct research producing higher levels of evidence.

\section{References}

1. Sackett DL. Rules of evidence and clinical recommendations on the use of antithrombotic agents. Chest. 1986;89(2 Suppl):2S-3S

2. The Journal of Bone and Joint Surgery (American) [Online]. 2011 Nov. [cited 2011 Nov] Available from http://www.jbjs.org/public/ instructionsauthors.aspx\#SubmissionManuscript

3. Obremskey WT, Pappas N, Attallah-Wasif E, Tornetta P 3rd, Bhandari M. Level of evidence in orthopaedic journals. J Bone Joint Surg Am. 2005;87(12):2632-8.

4. Kiter E, Karatosun V, Günal I. Do orthopaedic journals provide highquality evidence for clinical practice? Arch Orthop Trauma Surg. 2003;123(2-3):82-5.

5. Wolf JM, Athwal GS, Hoang BH, Mehta S, Williams AE, Owens BD. Knowledge of levels of evidence criteria in orthopedic residents. Orthopedics. 2009;32(7):494.

6. Hanzlik S, Mahabir RC, Baynosa RC, Khiabani KT. Levels of evidence in research published in The Journal of Bone and Joint Surgery (American Volume) over the last thirty years. J Bone Joint Surg Am. 2009;91(2):425-

7. Stirrat GM. Ethics and evidence based surgery. J Med Ethics. 2004;30(2):160-5.

8. Moseley JB, O'Malley K, Petersen NJ, et al. A controlled trial of arthroscopic surgery for osteoarthritis of the knee. $\mathrm{N}$ Engl J Med. 2002;347(2):81-8.

9. National Resident Matching Program; Association of American Medical Colleges. Charting outcomes in the match: characteristics of applicants who matched to their preferred specialty in the 2007 NRMP main residency match. 2nd ed [Online]. 2007 Aug. [cited 2011 Nov]. Available from http://www.nrmp.org/data/chartingoutcomes2007.pdf.

10. Bhandari M, Swiontkowski MF, Einhorn TA, et al. Interobserver agreement in the application of levels of evidence to scientific papers in the American volume of the Journal of Bone and Joint Surgery. J Bone Joint Surg Am. 2004;86-A(8):1717-20. 